\title{
Modeling the Best Practices Towards the Adaptation To The European Credit Transfer System in Technical Degrees Within The IEEE ES Chapter
}

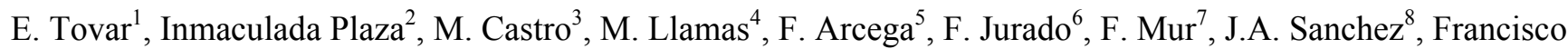 \\ Falcone $^{9}$ and Manuel Dominguez ${ }^{10}$
}

\begin{abstract}
Several Spanish universities have started their process of adaptation towards a common educational space as a first stage towards the implementation of the credit system as established by the regulation prior to 2010. These universities have developed several highlyilluminating experiences which could be useful to those teachers and institutions who have no previous references and models to develop new experiences of ECTS adaptation. To help these scholars and universities this paper reports on a project that has been recently completed and which has been supported by the Spanish Government and by the participation to the Spanish Chapter of IEEE Education Society. More specifically, the paper provides details about the management of the project, namely, details about the contributions of its three working groups, as well as the different tasks carried out and their monitoring. The paper also describes the results obtained with the project and provides assessment on previous pilot experiences presented by Spanish university teachers at Engineering Education Conferences as well as on the experiences compiled trough the project's web site.
\end{abstract}

Index Terms - Globalization: preparing faculty and students, mobility, ECTS.

\section{THE RoLE OF THE ECTS IN THE EUROPEAN Higher EDUCATION AND THE SPANISH CASE}

European countries face significant challenges in crossing international, cultural, and social borders in a common effort to build the European Space in Higher Education. The key factor in this complex process of promoting students' mobility is the implementation of the European Credit Transfer System (ECTS). This new concept of credit, that involves recognition of the real work of the student [1], provides the necessary instruments to understand and compare the different education systems more easily, to facilitate the recognition of professional qualifications for both national and international mobility, and to progressively increase the collaboration across European universities towards the convergence of educational structures.

Currently, the ECTS system is being used in most European countries, with the exception of some regions of Belgium, Portugal and Luxembourg [2]. Regarding those countries that are at present in the process of introducing the ECTS system, two different types of situation arise. On the one hand, there are countries which are directly incorporating the new credit system into their own systems because their previous systems were not based on credits. On the other hand, there are other countries that are adapting their current credit system to the European credit system. The Spanish Law for Universities states that "the Government will establish the rules in order to ensure that ECTS will be the unit of measure for all the courses from the official curricula (art. 88.3)" [3]. A more recent law [4] has established that the total number of credits required for a degree must be distributed among all the courses in accordance with the number of hours needed by the student to attain that specific degree. Then, the question is: how should we calculate and reach an agreement as regards how much time a student needs to achieve his/her learning targets? [5]. This calculation is based on the assumption that an average student can only do a certain amount of work in a certain amount of time. Since this calculation and the available total amount of time will probably differ, a common agreement will be needed and, most likely, several concessions will have to be made for the students. This process is not to be understated and requires overcoming the resistance that is likely to be put up by those involved in the process [6].

\footnotetext{
${ }^{1}$ Edmundo Tovar, Madrid Polytechnic University, Department of Software Engineering, 28660, Boadilla del Monte, Madrid, Spain, etovar@fi.upm.es

${ }^{2}$ Inmaculada Plaza, EduQTech, EUPT - University of Zaragoza, iplaza@unizar.es

${ }^{3}$ Manuel Castro, Spanish University for Distance Education, Electrical and Computer Engineering Department, E-28040 Madrid, Spain, mcastro@ieec.uned.es

${ }^{4}$ Martín Llamas, University of Vigo, Department of Telematic Engineering, E-36310 Vigo, Spain, martin@uvigo.es

${ }^{5}$ Francisco Arcega, University of Zaragoza, Department of Electrical Engineering, E-50018 Zaragoza, Spain, arcegafj@unizar.es

${ }^{6}$ Francisco Jurado University of Jaén, Department of Electrical Engineering, 23700 EPS Linares (Jaén), Spain, fjurado@ujaen.es

${ }^{7}$ Francisco Mur, Spanish University for Distance Education, Electrical and Computer Engineering Department, E-28040 Madrid, Spain, fmur@ieec.uned.es

${ }^{8}$ Jose Angel Sanchez, I.E.S. J.A. de Castro, E-45600 Talavera de la Reina (Toledo), Spain, jsanchez@talavera.uned.es

${ }^{9}$ Francisco Falcone, Navarra Public University, francisco.falcone@unavarra.es

${ }^{10}$ Manuel Domínguez, Leon University, diemdg@unileon.es
} 
At present, the Spanish universities have all begun their process of adaptation but at a different pace and all of them must have adapted to the new credit system before 2010 .

\section{EuropeAn Higher EdUCATION AREA (EHEA) ADAPTATION EXPERIENCES IN TECHNICAL DEGREES IN SPAIN: A REVIEW OF THE STATE OF AFFAIRS}

In the Spanish universities many teachers have shown interest in preparing their subjects for the adaptation to the European credit system. On a basic level, some of them have implemented the system on one single subject. When organised in groups, some other teachers have coordinated and supervised the adaptation of all the subjects corresponding to an academic year. Also actions developed from particular university institutions (e.g. faculties, polytechnics and schools) can be easily traced down. Prior to the project reported in this paper, several preliminary actions targeted at the European Convergence in Higher Education have been presented at Spanish conferences on education in technical degrees, for instance at the "University Conference of Educational Innovation in Technical Degrees- CUIEET" [7] Precisely, we chose the CUIEET conference held in 2006 to map out some of the Spanish initiatives (e.g. pilot projects) targeted at adapting to the EHEA. A total of 94 experiences were classified into the following types of initiatives:

- Development and application of computer tools suitable for the adaptation to the EHEA and the ECTS. The authors of these experiences agree that the new technologies must be used as a resource and aid so that technical teachers can carry out their teaching activities according to the EHEA regulations and guidelines. Among other learning tools and platforms Moodle was the commonest selected option for some of the authors. In their opinion, Moodle displays the following advantages. Firstly, the use of computer tools allows students to access a greater amount of teaching materials and information. Secondly, it facilitates the development of customized itineraries. In addition, it facilitates the development of specific applications aimed at favoring the adaptation to the EHEA, particularly, the development of tools for the design and management of educational guides and for the procedures derived or stemming from the adaptation.

- Development of teaching materials. The main goal of these initiatives is the development of multimedia materials and specific multimedia-based classroom assignments for the students. These materials can be used for imparting lectures and seminars, as part of the student's workload, for the students' private study, or for the preparation of projects and examinations. The materials can be accessed via the Internet. These authors highlight the usefulness of these materials in a learning environment in which the student becomes the main actor (i.e. responsible for his/her own learning process). The implementation of these teaching materials decreases the time used in explaining the theoretical concepts in the classroom. By this means the teacher can devote more time to other learning activities such as the development of practical assignments in the laboratory.

- Development of assessment tools and assessment criteria. Students' assessment was a topic that was tackled either explicitly or implicitly in several papers. From the results reported in these initiatives the following issues arise: assessment of courses and formative actions as part of non-presential courses/education or semipresential courses/education, assessment of the work done by the student and of the learning performance of the student through virtual platforms or through the student's regular attendance to class, and assessment of general and specific competences acquired by the students. A common feature in all the experiences is the implementation of ongoing assessment as the main assessment procedure.

- E-learning experiences. These experiences offer two alternatives: an e-learning course via a virtual campus and an isolated e-learning experience -the latter regarded only as a platform to carry out laboratory assignments. The materials used in these platforms consist in audio, video, text, documents, slides, etc. These pedagogical experiences allow the teacher to successfully complete the course planning and offer a more flexible learning environment, hence promoting students' autonomous learning.

- Adaptation of a specific subject to the EHEA credit system. In the adaptation of a specific subject to EHEA credits, the authors suggest several tasks to perform:

a) Definition of competencies and learning goals.

b) In the light of the learning goals, design of the syllabus, and specification of the methodology and the activities that the students have to carry out in the classroom and in the laboratory.

c) Selection of the computer tools and platforms that can be used as a teaching/learning support and/or for new teaching/learning methodological environments.

d) Detailed planning of the teaching procedures.

e) Specification of the assessment criteria and the assessment of the student's task performance. Also, specification of how the learning process is going to be supervised taking into consideration the specific learning goals as well as the students' planned activities and total workload.

These authors have compared the results obtained in the adapted subject with the results obtained with traditional teaching and assessment methods. However, no unanimous conclusion can be reached. Whereas some authors indicate that in the adapted subjects students' participation increased considerably, other authors state that students' participation was very poor. The authors also disagree as regards the workload of the students. Some of them indicate that student's workload increased considerably while others state that the students worked less hours than the expected ones. Finally, some teachers also indicate that the load distribution along the semester is very irregular (to put it simply, the students only 
concern about their learning targets when the semester comes to an end). In sum, all the experiences conclude that while the students' degree of satisfaction and motivation increase also does the work load of the teachers, the need for more facilities for the students' performance of their learning tasks (e.g. use of the laboratory without previous reservation), and the need for more adequate physical arrangement of the classes (e.g. a more suitable arrangement of the tables for group work, etc.). Some authors provide sample lessons and listings of advantages and disadvantages about their experiences. Both things, we believe, will be very useful for other teachers interested in developing similar experiences.

- Experiences of adaptation implemented in the subjects of a whole academic year, in a whole faculty/school, in a specific degree or in a whole campus. These experiences are representative of the joint work of teaching staff that are unifying efforts in preparing their adaptation to the EHEA. From this type of experiences we can highlight the following ones:

- Collaboration of teachers responsible for several subjects that have sought to coordinate transversal and specific competencies as well as the learning objectives of all their subjects. The coordination can be either vertical or horizontal.

- Development of subject specifications according to an institutional reference model.

- Preparation of teaching guides following an institutional reference model.

- Study of the total work load of the students.

- Study of the total work load of the teachers.

- Definition, specification and common agreement of the competencies of a specific degree -i.e. the so called "White Books".

- Implementation of the EHEA credit system in the subjects corresponding to a whole academic year.

- Design of the adaptation of a whole degree, indicating the stages fulfilled and those that still have to be achieved.

- Implementation of active and collaborative methodologies, ongoing assessment and new teaching /learning tools.

- Use of the EFQM (European Foundation for Quality Management) model and tools to introduce quality concepts.

- Awareness-building actions on the educational changes that are currently taking place and on the pace of the process towards the European convergence in higher education.

- Studies carried out to enquire into the degree of satisfaction of both teachers and students with the new credit system.

- Tracking of graduates.

- Organization of symposia to promote the interchange of educational experiences and information between teachers and students.

These pedagogical experiences have not only involved the collaboration of teachers of different subjects and knowledge areas but also the collaboration of different institutions and universities, with all the positive aspects that all this implies. It is important to highlight the need for an adequate coordination of human resources in this type of experiences, especially as regards how to harmonize the different activities, how to assess results and to optimize the process. Also, there is unanimity in two aspects: (i) the work of the teachers increases considerably and (ii) working with small groups is required to be successful in these pedagogical ventures.

- Development of new teaching guidelines teaching methodologies. When facing the adaptation to the EHEA, some authors provide useful guidelines that can help other teachers to start initiatives promoting the process of adaptation. These guidelines included general concepts and reflections on methodological aspects and advice on suitable pedagogical tools to use in adaptation experiences. Some examples of specifications and models of educational guidelines are presented, and all of them can likewise be applied to any other subjects or degrees. Also, some authors indicate that the advantages of offering a learner-centred approach as opposed to the traditional teacher-centred approach).

Generally speaking, the authors highlight the benefits obtained from sharing teachers' experiences regarding the above mentioned aspects as well as the advantages derived from the use of common reference models. The authors state that they are satisfied with the results obtained in these initiatives and, more specifically, with the positive response of the students towards the new methodologies. As a result, they strongly recommend these methodological procedures. In all, the papers presented at the conference offer useful guidelines on the methodological and pedagogical implications that the EHEA entails.

- Study of the motivation, awareness and involvement of the different participants in the EHEA adaptation process. The outcomes indicate:

- The Administration and University Services Personnel does not seem to have a clear knowledge about the EHEA. Therefore it would be necessary to develop activities intended to raise awareness on the implications of the EHEA and to provide this staff with the adequate background on the EHEA.

- The factors that influence the students' motivation, performance and involvement in the degree that they are currently studying have also been analyzed, as well as their awareness of the use of ICT by the teachers. These factors have been defined as key factors for a suitable adaptation to the EHEA and have allowed them to indicate a series of relevant aspects and ideas for the improvement of these teaching/learning experiences.

- Besides the aforementioned papers we can find several considerations and observations made by teachers which are explained taking into account the specific university settings in which these experiences have been developed.

\section{The Project}

October 10 - 13, 2007, Milwaukee, WI 
The current process adaptation to the new educational system has been the main focus of attention of the present project, which is supported by the Spanish Government and the participation of the Spanish Chapter of IEEE ES. The main goal of the project was to establish a descriptive model as common reference framework that could be applied to all the different experiences of adaptation to the ECTS. The second goal of the project was to collect the different experiences and interpret them according to this common reference model. The third goal was to develop a website which could serve to disseminate the best and most effective experiences of adaptation to ECTS in the technical degrees imparted at the Spanish universities. By this means, these experiences could become the breeding ground for future experiences with ECTS in any other school, faculty or university.

The preliminary outcomes of the ongoing project along 2006 were published as WIP paper at FIE06 [8]

\section{The Organization And the Process}

In order to achieve the goals of the Project, several work groups were defined, with different objectives, the latter depending on the outreach of the task or their specific role within the development of the project:

- A working group of voluntary members of the Conference of Deans and Directors of Computer Engineering (CODDI) of Spanish Universities. All these members belong to the same area of responsibility in the management in the European Space of Superior Education in their respective university centers. Their participation has been supported by the institutions they respectively belong to. They have contributed with experiences in the adaptation to the ECTS in Computer Engineering and have developed a descriptive framework that has been applied to all the experiences related to the implementation of the ECTS in Computer Engineering.

- A working group of the Network on the Spanish Chapter of IEEE: this network is funded by the Spanish Ministry of Science and Education (MEC) (grant TSI2005-24068-E), with the main aim of disseminating the "technological applications in the field of Education", ranging from its application in areas within IEEE (including experiences and pedagogical methods) to the design of tools and materials for teaching and learning. The Spanish Chapter of the Education Society (http://www.ieec.uned.es/ES/ accessed $19^{\text {th }}$ March 2007) was created in March 2004 by the members of the Education Society in Spain with the goal of complying with the guidelines of the Education Society within the Spanish geographical limits. The network comprises 74 researchers from 45 departments of 31 Universities. The group is formed by volunteers within the Spanish IEEE ES network. They all have a profile of educators in technical areas in Spanish universities. Their role in the project has been to disseminate the experiences developed in the above mentioned CODDI working group, especially, those contributions concerning the implementation of the ECTS credit system as well as the assessment and validation of the common descriptive reference model.

- A quality work group formed by two members of the Universidad del País Vasco and one international advisor whose task has been to establish quality criteria in the set of parameters used for the description of the experiences developed for the implementation of the ECTS.

- An Information Technology work group in charge of developing a web-based application. The group is formed by two assistants from the Universidad Politécnica de Madrid, both of them holding Computer Science Bachelor degrees and having a broad experience in web-based development and applications.

The development of this project has followed several work stages. Below, we detail these stages and the tasks carried out in each of them.

Stage 1. Gathering of experiences related to the development of the ECTS

1. Gathering of experiences from centers devoted to Computer Science Engineering. Several experiences in the adoption of the ECTS credit system were collected by the members of CODDI, paying special attention to those in which the members of the work group were directly involved. These experiences are all related to Computer Science degrees in Spanish Universities and they were all used as reference models for all future -multifariousadaptation models. They also intended to serve as examples to validate the descriptive reference model previously designed. Although these experiences did not follow any particular design or model, they were taken as the starting point to provide guidelines for the description of adaptation experiences. With this purpose in mind, each contributor explained his/her experience and assessed its implications within the specific university setting in which the experience was developed.

2. Gathering of experiences in Engineering Education university institutions. These experiences in ECTS adoption were also disseminated and transferred by members of the IEEE ES network to other engineering degrees.

\section{Stage 2. Building up a descriptive model of experience}

1. Definition of a descriptive reference framework carried out by the CODDI group. For each experience a peer review process was established, that is, two members of the work group together with the author of the experience participated in the review process. This assessment process was also improved with the presentation of the experiences in an open forum. The outcome of the forum was the development of an improved model which specified all the details, corrections and modifications of the initial experiences towards the ECTS adaptation. Later on, in a meeting held on 19 July 2006, a first draft of the descriptive model was presented and discussed thoroughly. The draft was based on the experiences 
gathered up to that time, and was intended to serve as the main source of analysis for assessing the success and the outcomes of the experiences. Special emphasis was placed on those aspects of the experience that fit into the descriptive model as well as on its feasibility of implementation -either total or partially- in other university contexts.

2. Review of the descriptive model by the IEEE group. This task was mainly carried out in the celebration of a special session within the program of the Congreso de Tecnologías Aplicadas a la Enseñanza de la Electrónica (TAEE'06, Technologies Applied to Education of Electronics Conference), held on 14th July 2006. This date facilitated the attendance and participation of other teachers who were not directly related to the project but that were none the less interested in the conference. The scheme of the session was to present the current status of project, its main objectives and several project-related experiences.

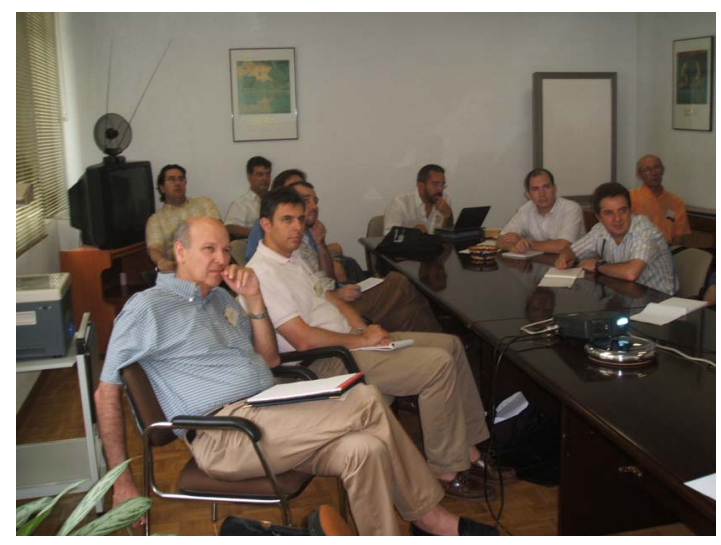

FIGURE 1

Picture of the IEEE workgroup meeting

3. Design of a set of specific indicators that could be applied to the ECTS experiences. At this stage it was thought that the selected experiences ought to be useful and representative enough to offer a detailed account of each individual experience to other universities as well as to those students who are interested in finding the most suitable destination centers for their mobility process. This stage allowed the identification of those specific indicators that can help identify whether an ECTS implementation experience is actually interesting and sufficiently representative for generalization. The identification of indicators was carried out in a meeting of the quality workgroup with the international advisor held on $18^{\text {th }}$ July 2006 . The indicators were taxonomized into the following profiles: Study Plan, Education Planning, Development and Assessment of Education, Human Resources, Material Resources and Services, academic results and the use of a Quality System in the experience

4. Application of the descriptive model to Computer Science Engineering and Technical degrees.
5. Model improvement. The descriptive reference model initially developed relying on the assessment of the previous experiences and initiatives was discussed by both workgroups. Finally an improved model was devised. The gathering of experiences was performed with the help of a web-based application located in the following url: http://marina.ls.fi.upm.es/ects/ (accessed 19 March 2007). Each member of the group provided at least one experience via the web-based application.

\section{Stage 3. Development of a website for ECTS implementation experiences}

1. A website was developed taking into account the description model resulting from the assessment of the ECTS implementation experiences as well as the needs identified by the work groups regarding:

- $\quad$ those students looking for information regarding ECTS implementation in centres and universities in order to decide possible mobility destinations.

- $\quad$ those universities looking for the best and most adequate experiences for the ECTS implementation.

The technical specifications of the website, which is hosted at the Universidad Politécnica de Madrid, were also detailed as well as the main features of the user interface both for universities and students.

\section{Stage 4. Broadcast}

1. An information leaflet was distributed in order to provide information about the development and the scope of the project and inviting to participate in it with questions and comments on the ECTS experiences included in the web.

\section{P5. Management and Coordination}

1. Development of a specific website for the project. As stated above, the project has been based on collaborative work by members from different geographical locations. The technical team decided to use Acollab as the main communication vehicle among the participants as well as a database for all the information generated in the project. Acollab is a freeware tool that allows different people to create a working group, share common files and documents, send newsflashes, program meetings, perform virtual meetings (chats), participate in fora and send mails. The version used has been improved by the Gabinete de Tele-Educación (remote learning committee) of the Universidad Politécnica de Madrid in order to offer the best service from its servers. 


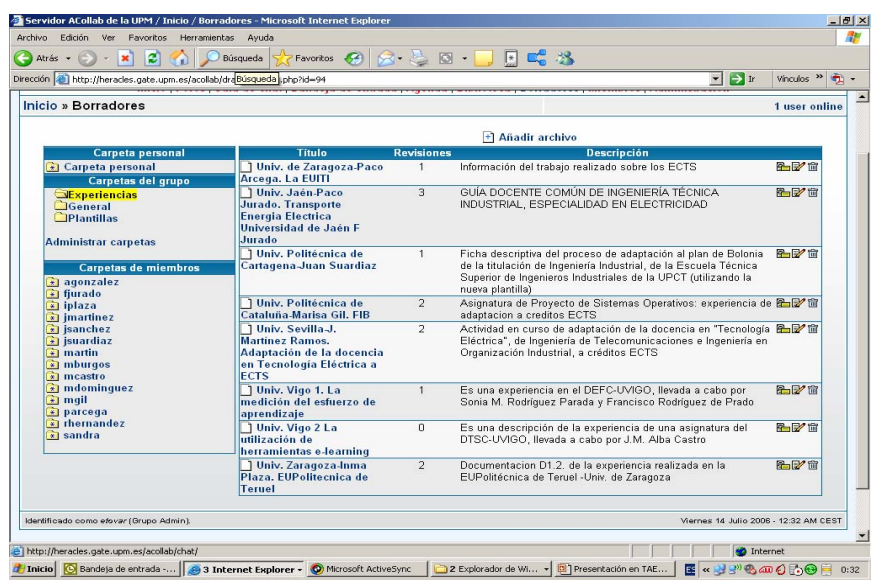

FIGURE 2

Screen with information on the Project's use of Acollab

\section{RESULTS}

After a detailed analysis of the experiences presented at the CUIEET 2006 Conference of Educative Innovation for Technical Degrees, the present project sought to offer assessment of these previous experiences and provide more suitable guidelines for the development of similar adaptation experiences. The presentations of the 94 selected communications were illustrative of the considerable effort that at present is being made with regards to the adaptation of technical degrees in Spanish universities to the new credit system. Additionally the need to disseminate these experiences and the need to compare and assess them thoroughly will eventually serve to facilitate the work of other scholars and institutions in the ECTS implementation process.

The results of this project can be consulted on the URL http://marina.ls.fi.upm.es/ects (accessed 19 March, 2007). Below, the main results are briefly described:

- The definition of a general reference model to describe the experiences. This model has been key to guarantee the fulfilment of the project's objectives. In our opinion, the usefulness of this model primarily relies on the suitable election of the description parameters. For this reason the selection and description of these parameters was assigned to those members who had a broader experience in carrying out this particular task.

- The common reference model was included in a web portal. This portal contains an application form to fill in with information about a new ECTS adaptation experience. By this means users can incorporate their experiences to the website. The web-based application also provides other features for navigation and users' consultations about the set of experiences compiled in this project.

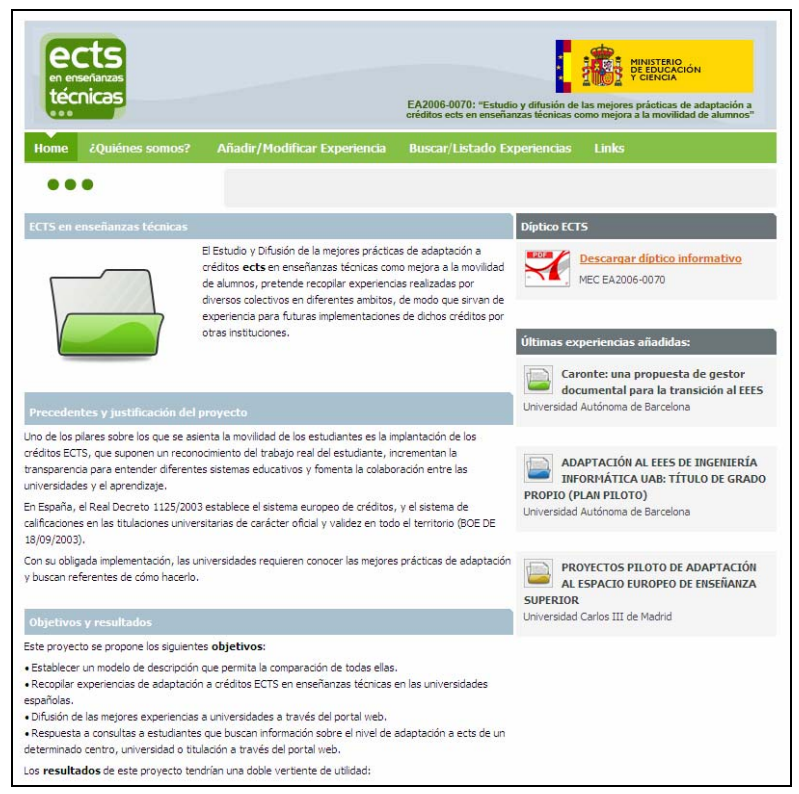

FIGURE 3

Home page of the project website

- Repository of experiences compiled in the portal.

- A statistical program which provides information on the types of experiences compiled in the repository web of the project as well as the exact date in which each experience report was added to the web. Rather than reflecting the current status of the adaptation process towards the ECTS, these experiences specifically reflect the current tendency of the adaptation process at that particular time. The different types of users' consultations through the web can be sorted by the following parameters: type of dissemination of the experiences to other universities and degrees, types of objectives for each specific experience, types of sponsors, types of funding (with/without external funding), number of students and teachers involved in the experience, and types of resources generated from the experiences.

- Possibilities of providing help to the teaching staff interested in adapting to the new educational guidelines. This can be done through consultations that provide access to the most suitable ECTS implementation practices.

- Additionally, several recommended criteria as well as a set of quality standards are provided to the user so that he/she can start a new adaptation venture similar to those compiled in this project.

- Aid to students' mobility, providing information on a given degree, centre or university in an effort to adapt to the EEES. By this means the students will be able to take clearer decisions when selecting a university center to further their studies abroad.

At the moment of closing of this report 33 experiences have been compiled so far and have been included in the 
electronic portal with the aim of providing detailed information for both teachers and students. Although we are aware that this number is relatively small, it has none the less proved to be satisfactory to validate the descriptive reference model and to obtain a good sample of the present casuistry.

\section{Open questions}

Still, several questions remain to be answered and we invite other academics to find a response and a common agreement in the light of the results obtained from previous experiences and results. A key question is how to obtain the maximum efficiency in the work done so far towards the ECTS adaptation process. One possible solution, as the present project has sought to find, is by compiling and disseminating the maximum amount of experiences. A forthcoming information campaign on the web will be addressed to those authors who have already developed one of these adaptation experiences. In the near future, we also expect to broaden the sample of experiences compiled in the present project with experiences coming from other European countries.

\section{ACKNOWLEDGMENTS}

This project has been developed thanks to the financial support of the Spanish Ministry of Science and Education (project EA2006-0070) within the special program oriented to the quality improvement in Higher Education.

\section{REFERENCES}

[1] European Universities Association, 'European Credit Transfer and Accumulation System (ECTS) - Key Features' November 2002 (unpublished document).

[2] Eurydice, Directorate General for Education and Culture "Focus on the Structure of Higher Education in Europe" European Commission, http://www.eurydice.org/, 2003. Accessed 19 March 2007.

[3] Ministerio de Educación, Cultura y Deporte, "Ley Orgánica de Universidades", art. 88.3, December 2001.

[4] Ministerio de Educación, Cultura y Deporte, "Real Decreto 1125/2003”, Boletín Oficial del Estado, num.224. September 2003.

[5] R. Wagenaar, Workload and the calculation of ECTS Credit Points, University of Groningen, September 2000.

[6] E. Tovar, Analysing the problems of the implementation of the european credit transfer system in a technical university, Frontiers In Education 34th ASEE/IEEE Frontiers in Education Conference, October 20 - 23, 2004, Savannah, GA.

[7] "Congreso Universitario de Innovación Educativa en las Enseñanzas Técnicas" Gijón, Spain, 27-29 September 2006 http://cuieet14.euitig.uniovi.es/congreso/bienvenida.php. Accessed 19 March 2007.

[8] E. Tovar, M. Castro, M. Llamas, F. Arcega, F. Jurado, F. Mur, J.A. Sanchez, Inmaculada Plaza, Francisco Falcone and Manuel Dominguez, "Modeling the best practices of adaptation to European credit transfer system in technical teachings as improvement to the mobility of students", 36th ASEE/IEEE Frontiers in Education Conference, October 28 - 31, 2006, San Diego, CA. 